Atilio Raúl Rubino

\title{
Literatura/cine : el cuerpo y la sexualidad en los textos culturales de Doris Dörrie y Martín Rejtman
}

\begin{abstract}
Avertissement
Le contenu de ce site relève de la législation française sur la propriété intellectuelle et est la propriété exclusive de l'éditeur.

Les œuvres figurant sur ce site peuvent être consultées et reproduites sur un support papier ou numérique sous réserve qu'elles soient strictement réservées à un usage soit personnel, soit scientifique ou pédagogique excluant toute exploitation commerciale. La reproduction devra obligatoirement mentionner l'éditeur, le nom de la revue, l'auteur et la référence du document.

Toute autre reproduction est interdite sauf accord préalable de l'éditeur, en dehors des cas prévus par la législation en vigueur en France.
\end{abstract}

\section{revues.org}

Revues.org est un portail de revues en sciences humaines et sociales développé par le Cléo, Centre pour l'édition électronique ouverte (CNRS, EHESS, UP, UAPV).

Référence électronique

Atilio Raúl Rubino, «Literatura/cine : el cuerpo y la sexualidad en los textos culturales de Doris Dörrie y Martín Rejtman », TRANS- [En ligne], | 2014, mis en ligne le 24 février 2014, consulté le 28 février 2014. URL : http:// trans.revues.org/978

Éditeur : Presses Sorbonne Nouvelle

http://trans.revues.org

http://www.revues.org

Document accessible en ligne sur :

http://trans.revues.org/978

Document généré automatiquement le 28 février 2014

Tous droits réservés 


\section{Literatura/cine : el cuerpo y la sexualidad en los textos culturales de Doris Dörrie y Martín Rejtman}

\section{Introducción}

Cuando, en 1996, Martín Rejtman estrena Rapado [1992], su primer largometraje, no se le dio la importancia que tendría más adelante. Con el tiempo, se convirtió en una película precursora de lo que se conocería como el Nuevo Cine Argentino. Las temáticas de la película, la forma narrativa, los personajes, etc., rompían con lo que se venía haciendo en el cine anterior. Casi una década antes, en 1984, Doris Dörrie estrena en la República Federal de Alemania (RFA) la película que la haría exitosa en todo el mundo, Männer... También con ella en el ámbito alemán nace un nuevo período en el cine que deja atrás las búsquedas, temáticas y estilos del Neuer Deutscher Film.

Tanto Dörrie como Rejtman tienen la extraña cualidad de dedicarse a dos actividades, la literatura y el cine, sin que una relegue a la otra ${ }^{2}$. En ambos casos, es necesario pensar su escritura literaria en relación al cine y al campo del cine. Ambos vuelven la vista sobre el presente para retratarlo caracterizado por cierto desgano. Como modo de oponerse a la seriedad del cine anterior, apelan al artificio del absurdo y a la comicidad. Los distintos relatos literarios y cinematográficos de Rejtman van a estar ocupados por personajes que parecen vacíos de ideología, de política, errantes, como fantasmas. Los personajes de Dörrie, por otro lado, también dan cuenta de una época en la que se han perdido los ideales que los caracterizaron décadas antes.

Este trabajo se propone analizar los textos literarios y cinematográficos de la alemana Doris Dörrie y el argentino Martín Rejtman, haciendo especial énfasis en la representación del cuerpo y la sexualidad y su entramado con los procesos identitarios. En efecto, resultan interesantes las coincidencias en el tratamiento de las identidades como algo que, en los textos culturales de Rejtman y Dörrie, se busca pero nunca encuentra su centro, como algo movible que intenta fijarse en objetos y elementos que resultan superficiales y momentáneos, pero sobre los que se asienta todo el peso de una identidad fracturada por ese pasado que no se quiere o no se puede revisar. Al mismo tiempo, la mirada sobre el propio cuerpo se vuelve extrañada, puesto que lo que le otorga esa identidad resulta ajeno y transferible.

Para esto, tomamos conceptos e ideas provenientes de los estudios queer y la teoría postestructuralista, fundamentalmente en el tratamiento de las identidades y los cuerpos. En particular, nos interesa la crítica del postestructuralismo a la idea moderna de identidad entendida como algo idéntico, fijo, sostenido en el tiempo, con unidad y coherencia y las reelaboraciones que realiza Judith Butler (1990 y 1993), así como las conceptualizaciones de Beatriz Preciado sobre el régimen actual de control de cuerpos y subjetividades, al que llama farmacopornográfico (2008) y sobre el cuerpo protésico (2002).

Tanto Dörrie como Rejtman se oponen a la necesidad de tratar temáticas de importancia y fuerte peso social y político que se podía apreciar en los campos culturales anteriores, en especial, el nazismo y la postguerra en el Neuer Deutscher Film y la dictadura militar en el cine argentino de la recuperación democrática argentina. Emilio Bernini afirma que con Rapado se abre una nueva línea en el cine argentino "que ya no responde a los intereses característicos de los cineastas de la década del 80, que en gran parte se habían volcado a revisar, de modo no siempre parejo, el proceso político impuesto por el terrorismo de Estado en la década anterior" (2008 : 8). Algo similar puede decirse respecto a Doris Dörrie, ella rompe con los imperativos del Neuer Deutscher Film al realizar películas que tienen la mirada puesta en la Screwball Comedy norteamericana y que rechaza las temáticas tratadas hasta entonces en pos 
del tratamiento de relaciones románticas y la recuperación de una mirada femenina sobre las relaciones de pareja. Su visión del presente, sin embargo, resulta bastante desganada. En sus textos literarios y cinematográficos se puede apreciar una desilusión respecto a los ideales reformistas que tuvo la generación del 68 alemana.

Tanto Dörrie como Rejtman recurren a elementos de la comedia para romper con lo que se venía haciendo en el cine y esta ruptura con un campo principalmente cinematográfico es lo que se aprecia también en sus textos literarios, que no pueden ser entendidos en toda su significación sin atender a sus películas. Sus textos dan cuenta de una época que se caracteriza por la despolitización y el vaciamiento ideológico. Asimismo, son parte de un nuevo proceso de búsqueda estética literario-cinematográfica que les permita representar una realidad y una experiencia generacional para la que los sistemas de representación y las retóricas cinematográficos al alcance ya no eran suficientes o bien resultaban obsoletos.

\section{Los cuerpos-objeto y el problema de la identidad}

Es evidente que entre los relatos literarios y las películas de Martín Rejtman existe una fuerte unidad. Podemos decir que ambos forman parte de un mismo proyecto creador. Rocío Gordon denomina al estilo de Rejtman "estética de la inercia" :

"Sus textos y películas crean un mundo aparentemente sin motivaciones que podría estar formulando una mirada sobre la contemporaneidad. La base de esta estética radicaría en la postulación de una movilidad generada por una concatenación de eventos, pero que no tienen ni causas ni finalidades concretas" (Gordon, $2001: 290$ ).

Los personajes de Rejtman no persiguen una finalidad ni se mueven motivados por razonamientos o decisiones de importancia, sino que actúan de manera caprichosa, infundada. Se caracterizan por la apatía, pues pareciera que todo les da lo mismo. En ese contexto de personajes que se mueven sin motivación alguna, de relatos que no tienen un fin (Bernini, 2008 : 36), etc, las identidades aparecen fracturadas, descolocadas, descentradas. Los personajes son tratados narrativamente como objetos (muchas veces, objetos de mercado) $\mathrm{y}$, en cambio, los objetos adquieren una importancia desmedida, una densidad simbólica que reemplaza las identidades de las personas.

Por ejemplo, en el caso de la película Silvia Prieto (1999), hay un conjunto de personajes que parecieran no tener rasgos centrales o personales que los distingan y que, en cambio, se caracterizan por su movilidad. Se puede ver claramente en las tres parejas de la película. Silvia (Rosario Blefari) y Brite (Valeria Bertucelli) se intercambian los ex-maridos : Silvia comienza a salir con Gabriel (Gabriel Fernández Capello), el ex-marido de Brite, quien sale con el exmarido de Silvia, Marcelo (Marcelo Zanelli). La tercera pareja de la película está conformada por Garbuglia (Luis Mancini) y Marta (Susana Pampin), quienes se conocieron en un programa de televisión y cuya relación se basa en los lazos comerciales que establecen con el canal ${ }^{3}$. En este contexto de personas intercambiables, los objetos adquieren mayor dimensión simbólica, supliendo esas identidades vaciadas de los personajes. Hay una serie de objetos que pasan de mano en mano y van obteniendo una densidad mayor que los propios personajes. Muchos de estos elementos, a su vez, dan nombre a los personajes y, con ello, le dan carnadura, densidad interior. Se definen más por estos objetos, que son variables e intercambiables, que por una suerte de interioridad inmóvil o esencial, inexistente en los personajes de Rejtman ${ }^{4}$. El elemento más importante es el que le da el título, el nombre de la protagonista. Pero hay otros. Uno de ellos es el saco Armani que Silvia roba, el cual prestará su nombre al dueño del mismo. Luego, le regala el saco a Gabriel, quien se lo vende a Marcelo y éste, a su vez, debe vendérselo a su dueño original, Armani. Otro objeto importante es la lámpara que Silvia hace con una botella de whiskey que toma Gabriel para regalársela a Silvia Prieto 2 (Mirta Busnelli) pero que, sin embargo, se arrepiente y se la da a Gabriel, quien, de adolescente, era llamado "lámpara de botella". Brite, por otro lado, lleva el nombre del jabón en polvo del cual es promotora. Otro elemento es la muñequita-Silvia Prieto. Gabriel la trajo de Los Ángeles para regalársela a su ex mujer porque le recordaba a ella. Brite, sin embargo, se ofende y considera que es más parecida a Silvia, a quien se la regala. Luego Silvia se deshace de ella tirándola. Uno de los pocos primeros planos de la película sigue los acontecimientos de la muñequita 
tirada, hasta que un chico la recoge ${ }^{6}$. Otros objetos, como el canario, el tapado o el contestador automático, tienen una función similar en la película. Según Emilio Bernini,

\begin{abstract}
"los nombres repetidos remitirían en el filme menos a un problema de identidad que a circuitos de intercambios que tienen su base en una construcción plana de los personajes o en una suerte de interioridad vaciada por las cuales es posible trabajar el nombre como significante y abrir así juegos que culminan en el documental con las Silvia Prieto reales, con lo que, aquí, nada diferencia al documental de la ficción" (2008: 38).
\end{abstract}

El intercambio y circulación de un nombre también se da en otras de sus películas y en algunos cuentos. Por ejemplo, en "Núber" (Rejtman, 2007, 7-16), el nombre que da título al cuento va adquiriendo diferentes sentidos a lo largo del relato. Primero es un nombre sin significado ni referencia (no se sabe si refiere a una persona o a un perro), luego es un conejo (aquí ya simboliza las diferentes figuras masculinas en el cuento : el padre de Ana, su novio y el novio de su madre). Finalmente, se pierde en medio de una masa de conejos, en la que resulta imposible distinguirlo y pasa a ser todos o cualquiera de ellos.

Por otro lado, en los textos literarios y cinematográficos de Dörrie también se puede encontrar un cuestionamiento a las identidades entendidas en un sentido esencialista, sólo que en la obra de Dörrie lo que termina de completar a los personajes y dotarlos de identidad son las vestimentas y apariencias. En efecto, en sus textos literarios y cinematográficos, las identidades se encuentran muy intrincadas con lo superficial, con lo que recubre el cuerpo. Elementos como el disfraz, la máscara, el traje, la (segunda) piel, el maquillaje, el peinado, la vestimenta, etc, adquieren una dimensión simbólica similar a la que veíamos en Rejtman. Sin embargo, aquí las identidades se constituyen a partir de la visión del otro, de lo que se ve, de lo que se percibe, por eso éstas pueden mutar al cambiar las apariencias. Un ejemplo lo constituye la novela Der Mann meiner Traüme, que aborda el mundo de las apariencias. Su protagonista es una supermodelo, Antonia, que debe hacer uso de todas las tecnologías cosméticas para mantener su imagen, incluso en contra de su salud. Ella se obsesiona con la imagen de un joven en una pintura de Botticelli de 1474, hasta que encuentra a alguien idéntico a la imagen del cuadro, Johnny, un vagabundo, un mendigo que pide limosna con una lata vacía. La historia se centra en la relación de estos dos personajes. Pero Johnny no es realmente un homeless, sino que adopta ese estilo de vida por una postura política de lucha contra el sistema capitalista. Es, por consiguiente, un falso mendigo, pues cuenta con una fortuna heredada y a raíz de este hecho decide tener ese estilo de vida. Puede hacerlo porque no tiene de qué preocuparse, lleva una vida acomodada y ha podido estudiar las carreras de moda. Cuando ella intenta cortarle el pelo largo y sucio mientras él duerme, se enoja muchísimo, lo que indica que la postura comprometida y política no es menos superficial que el mundo de las apariencias de ella. Su hippismo, su actitud anti-capitalista es también apariencia, moda. En ambos casos se trata de imágenes, las identidades se constituyen en lo que se ve de uno, en la superficialidad. La novela acerca esos dos mundos, el de la superficialidad absoluta y el del compromiso político y desinterés por las apariencias, para mostrar que no están tan alejados o bien que ya todo está gobernado por el poder de las imágenes y los estereotipos. Para Dörrie la postura políticamente comprometida y la superficial de la supermodelo no son tan diferentes en el fondo. Todos estamos hechos de apariencia, también el hippie, por eso sus ideales, si realmente los posee, deben tener un correlato visible, deben ser imagen, hacerse cuerpo, para existir.

\title{
Los cuerpos protésicos y los cuerpos-envase
}

En el caso de la película Los Guantes Mágicos (2003) de Martín Rejtman se podría hablar, en términos de Beatriz Preciado (2002), de cuerpos protésicos. Los personajes completan su entidad con objetos que los complementan y sin los cuales están incompletos : el auto para Alejandro (Gabriel Fernández Capello), las pesas y aparatos de gimnasio para Luis (Diego Olivera), su disco para Piraña (Fabián Arenillas). En los casos de Susana (Susana Pampin), Cecilia (Cecilia Biagini) y Leonardo (Leonardo Azamor), por otro lado, tenemos cuerposfármaco. Se relacionan entre sí a partir de la enfermedad, los síntomas y los medicamentos. Así, resultan cuerpos tecnologizados por el aparato médico y farmacológico, son cuerpos 
discursivos que se dicen, se pronuncian, "las cuestiones del cuerpo en su mayor parte se cuentan, se nombran, como para no olvidar que el cuerpo siempre está ya atravesado por el lenguaje (incluso en la acción muda), que no hay experiencia del cuerpo sin más, que el cuerpo es también interpretación" (Sanjurjo, 2007 : 144). Las enfermedades y sus síntomas aparecen primero enunciadas y luego se hacen carne. Como actos performativos del lenguaje, las palabras se hacen cuerpo. Estos personajes son cyborgs, cuerpos tecnológicos, pero asexuados : la libido se fija en los objetos y no en cuerpos humanos. En esta película, la sexualidad es vista de manera distanciada y deconstruida. No hay ni deseo ni placer sexual. Los actos sexuales forman parte del mismo intercambio de objetos y personas, son un bien de mercado o forman parte del deambular errante de los personajes, de la maquinaria cotidiana, de la rutina que los aliena. Se constituye un cuerpo-máquina. El cuerpo de Luis, el actor porno, por ejemplo, es construido por los fierros, los aparatos de gimnasio, y su alimentación. Su cuerpo es su trabajo. Es un cuerpo pornográfico. En la película, el sonido del jadeo de la ejercitación y del acto sexual filmado para una película porno se confunden y generan como una música, una melodía, que es también el ruido monótono de una máquina, como ocurría con la caja registradora en el cuento "Barras" (Rejtman, 2011 : 39-71), de una fábrica posmoderna que elabora y moldea cuerpos. Además, cuando todos ven la película porno que Luis filmó en Argentina, ni siquiera su hermano puede distinguir su cuerpo deshumanizado (objeto) en la maquinaria porno-sadomasoquista. Si pensamos en términos de lo que Beatriz Preciado (2008) llama régimen farmacopornográfico, es decir el régimen actual en el que los sujetos ya no son controlados mediante un disciplinamiento externo, como sostenía Foucault (1977), sino que las tecnologías de subjetivación actúan desde adentro, se convierten en cuerpo, entonces estos cuerpos de Los Guantes Mágicos serían una estilización cómica de los cuerpos entendidos en términos posmodernos, una dimensión que remite a, en palabras de Mariana Sanjurjo (2007), "una no claridad de las fronteras, a zonas donde lo propio es ya irremediablemente inapropiable, y a la sospecha de que incluso la materialidad del cuerpo es siempre ya máscara, de que no hay desnudez posible" (145).

En Cuanto a Dörrie, hay que tener en cuenta que en sus películas y textos literarios los cuerpos, las identidades y las prendas de vestir constituyen una unidad difícil de disociar y en la que los límites entre uno y otro no son fáciles de determinar. Por eso se puede hablar de cuerpo-envase, ya que las vestimentas devienen prótesis que continúan la extensión del cuerpo volviendo imposible la delimitación de adentros y afueras. Así, el cuerpo-envase es un significante que deviene de enorme simbolismo en la película que la hizo famosa, Männer... Su protagonista, Julius es un artista gráfico devenido empresario exitoso del diseño de envases. La trama gira en torno a su relación con Stefan, el amante de su esposa, un hippie que trabaja freelance y no se preocupa por el dinero. Julius se convierte de yuppie en hippie para engañar a Stefan e incitar la transformación contraria en él. Las transformaciones están marcadas por el cambio de la vestimenta : el traje en Julius y los jeans en Stefan son vistos como pellejos, segundas pieles, que dan identidad a los personajes. Se trata de dos modelos de masculinidades que se relacionan con la generación del 68 : "as graphic designers they are linked to visual artist from the generation of 1968" (Taylor, 2004 : 45). Además del cuento "Männer", en el que se basa la película, los otros relatos que componen su primer libro, Liebe, Schmerz und das ganze verdammte Zeug, también se centran en este tipo de transformaciones. En "Geld", Carmen se transmuta de ama de casa fea y gordita en femme fatal (y en una ancianita, y en una dama extravagante y en un señor). En "Mitten ins Herz", Anna cambia de personalidad cuando tiñe su cabello de azul y, como una especie de Mr Hyde, se convierte en asesina. En "Paradies", Lotte, una campesina vulgar, se convierte en Angelika, su amiga de la infancia, una mujer de ciudad, y consigue obsesionar al marido de ésta. Hay en el fondo de estas transformaciones un constante deseo de ser otro que tiene que ver con el lugar que ocupan las personas y sus individualidades en las sociedades desarrolladas. Pero al mismo tiempo se cuestiona que lo que en verdad hace a la identidad de las personas sea esa apariencia. 


\section{Cambio generacional}

Tanto en Dörrie como en Rejtman, los tratamientos de la cuestión de la identidad vienen de la mano de un fuerte cambio generacional que implica no sólo variaciones en cuanto a las temáticas ficcionales sino también en cuanto a estéticas y visión del mundo. Por eso, las identidades estables, incuestionables, coherentes y fijas de muchos de los relatos cinematográficos de corte épico de las generaciones anteriores son fuertemente cuestionadas por Dörrie y Rejtman mediante este tipo de tramas y personajes.

Es el caso del cuento "Rapado" de Rejtman. Cuando Lucio, el protagonista, pierde su moto, objeto que lo completaba, decide raparse la cabeza. De manera simbólica, se trata de vaciar la cabeza de los significantes que son ajenos, impuestos por la generación anterior, aquella que usó el pelo largo como rebeldía frente a las normas y como símbolo de liberación del cuerpo. Al respecto, es interesante mencionar un cuento que ya desde su título resulta muy irónico respecto a los sentimientos generacionales. Me refiero a "Algunas cosas importantes para mi generación" (Rejtman, 2007 : 87-112). El cuento comienza así : "Hay ciertas cosas que mi novia me dice demasiado seguido. Por ejemplo, el sábado pasado no se cansó de repetirme que quería que me cortara el pelo" (Rejtman, 2007 : 87). Aquí aparece el cabello como algo muy importante, constitutivo de lo que esta persona es. Sin embargo, no tiene el mismo significado que tenía el pelo largo para la generación anterior, pues aquí no se lo hace significar libertad y liberación del cuerpo : "Entré al baño, me desvestí y me metí bajo la ducha. El agua pegó contra mi cuerpo y tiré la cabeza hacia atrás : ahora que tenía el pelo completamente mojado pensé que nada en el mundo podía hacer que me lo cortara" (Rejtman, $2007: 88$ ). Esta relación con la generación anterior también puede verse en Los Guantes Mágicos. Los personajes de esta película están cerca de los cuarenta, fueron jóvenes en los 70 . Lo que marca el puente con esa época es el recital de León Gieco que funciona como leitmotiv en la película. Se trata de la canción "Hombres de hierro" interpretada en el Buenos Aires Rock, 1971. Cada vez que aparece en la televisión, los personajes se quedan mirando paralizados. Como comenta el propio Rejtman :

"Tiene que ver con el estado de un personaje de cerca de 40 años hoy, en el momento de hacer la película, y el estado de ese personaje veinte años antes. Ve ese video y podría ser una de las personas que está entre el público. Se ven planos del público. Yo me encontré un día haciendo zapping, viendo esa escena de "Rock hasta que se ponga el sol" en la televisión, y me quedé boquiabierto : ‘¿Qué es esto que estoy viendo ?’. ¿Cómo pudimos haber llegado hoy a lo que llegamos ? ¿Cómo puede ser que hayamos sido así, que hayamos tenido esa frescura, esa ingenuidad?’ (Bernini, $2008: 83$ ).

Cuando los personajes se enfrentan a este video, es como si se vieran a sí mismos y no supieran qué pasó con ellos, como si no se reconocieran, porque aquello que fueron, por lo que lucharon y en lo que creyeron se dejó atrás para (sobre)vivir en un mundo gobernado por la apariencia y el mercado, un mundo sin posibilidades de trascendencia ni personal ni, mucho menos, grupal, generacional.

Desde la realización de su primera película, Rapado (1992), Martín Rejtman se constituyó en referente de una nueva generación de cineastas argentinos. Algo similar puede decirse de Doris Dörrie casi una década antes en el ámbito alemán. Cuando en 1984 estrena Männer... tomando como modelo la comedia norteamericana, nutrida por exiliados como Billy Wilder y Ernst Lubitsch, ésta se convierte en un inusitado éxito, cosechando, sin embargo, las críticas más desvastadotas. A partir de esta película, la realizadora construye su universo literario y cinematográfico en clara oposición a ciertas tendencias de lo que se llamó el Neuer Deutscher Film. En particular, se puede decir que los representantes del Neuer Deutscher Film se preocupaban por asuntos de importancia humana, por los problemas de la juventud y la revisión del pasado histórico y la posguerra, así como por una renovación y experimentación formal. Doris Dörrie evita la densidad política, ideológica y formal que caracterizó al Neuer Deutscher Film, para proponer comedias románticas al estilo norteamericano. Sin embargo, no se la puede considerar ligera, superficial y apolítica. Sus primeros relatos dan cuenta de una época de despolitización, representan el desinterés que se vivió durante la cancillería de Helmut Kohl (1982-1998) (Utz, 2004 : 180). Muchos de sus textos pueden leerse como una critica 
a los jóvenes del 68 por haber dejado de lado los ideales de cambio social que sostuvieron en las décadas anteriores para ocuparse del crecimiento socio-económico individual.En este sentido, Dörrie critica a la generación alemana que planteó en los sesentas ideales reformistas y revolucionarios. Los jóvenes del 68 querían cortar vínculos con las generaciones anteriores, pues las consideraban todavía cómplices del nacionalsocialismo, querían deshacerse de los ideales burgueses y capitalistas y buscaban un mundo mejor, con igualdad no sólo social sino también sexual. Lo que denuncia Dörrie en los cuentos y películas de su primera etapa es que esta generación creció olvidando esta época e intentando conseguir únicamente su propio beneficio socio-económico personal. La cuestión de fondo es un planteo que considera las identidades como algo muy intrincado con la apariencia física y con lo superficial, unas identidades que no encuentran su centro y por eso se fijan en trajes, envases, máscaras, apariencias, piel, cuerpos. Y en ellos se asienta el peso de una identidad descentrada y en fuga, fracturada.

\section{Conclusiones}

A modo de conclusión, es preciso preguntarnos el porqué de esta unión que parece un tanto injustificada entre una alemana a mediados de los años ochenta y un argentino a principios de los noventa. El acercamiento y la comparación de dos autores tan alejados en el tiempo y en el espacio quizá nos permitan apreciar cómo se dan procesos similares en ambos casos. Tanto la dictadura militar en Argentina como el Tercer Reich en Alemania han sido momentos históricos que marcaron a varias generaciones posteriores, incluso a aquellas que no los han vivido o que no poseen recuerdos sobre ello. Es muy interesante cómo en autores y cineastas que intentan evitar ciertos temas tan concurridos (y, por eso, muchas veces cristalizados y anquilosados) en las generaciones anteriores, aparece como tema recurrente la cuestión de la identidad y cómo en ésta aflora la marca de ese pasado doloroso (vivido o no), que aunque se quiera evitar, está ahí. Tanto en el caso de Rejtman como en el de Dörrie, se puede decir que ambos dan cuenta de nuevas realidades que no se podían contar con el sistema de representación anterior (sobretodo cinematográfico). De esta forma, los cuerpos, saturados por esos discursos sociales que hegemonizaron el campo cinematográfico anterior, se revelan tratando de deshacerse de ellos o bien evidencian su carácter superficial y transitorio al poder mutar como se cambia un vestido. El cuerpo-envase de Dörrie pone de manifiesto y denuncia cómo la generación del 68 dejó de lado las perspectivas políticas e ideológicas en pos del beneficio socio-económico personal. El cuerpo-objeto de Rejtman denuncia el carácter de bien de mercado en que se han convertido las personas. Pero, a su vez, muchos de sus personajes logran deshacerse del imperativo económico y generan un valor-otro, un valor propio, no económico, a partir del capricho, del sinsentido, que revierte la racionalidad moderna. Por lo general, se trata de un volver a empezar, como de un volver al grado cero de la significación de los cuerpos para desligarlos de las tradiciones discursivas que los han constituido.

Según Beatriz Sarlo, Rejtman da cuenta de una época de vaciamiento ideológico y político, de "un mundo sin cualidades, un mundo del postrabajo, de identidades planas, sin volúmenes," (2003 : 142). Sarlo afirma que estos tipos de trabajos, sólo cuantitativos "no hacen a la identidad del sujeto, no le proveen un suelo que lo constituya" (Sarlo, 2003 : 134). Elsa Drucaroff, en cambio, encuentra gestos de rebeldía e inconformismo en la banalidad y el capricho de sus personajes (Drucaroff, 2011 : 125). En esa errancia que los caracteriza, en esa movilidad constante, Drucaroff ve la ruptura de los puentes intergeneracionales (Drucaroff, 2011 : 323), la falla en la generación anterior que no ha sabido hacerse cargo de sus fracasos y dejar lugar a los más jóvenes. Desde esta perspectiva, raparse la cabeza es oponerse a ese sistema de sentidos heredado y obstruido, pero dejarse el pelo largo también lo es, porque el cuerpo comienza a significarse a sí mismo, comienza a ser solamente cuerpo, lo que no es para nada poco. 


\section{Notes}

1 Se denomina Neuer Deutscher Film al período cinematográfico de la República Federal Alemana (RFA) que va desde 1962 (la firma de lo que se conoce como el manifiesto de Oberhausen) hasta 1982 (la muerte de uno de sus exponentes más destacados: Rainer Werner Fassbinder). El Neuer Deutscher Film estuvo constituido, básicamente, por una nueva generación de jóvenes realizadores que se proponían renovar un cine que consideraban anquilosado. A grandes rasgos, se trató de un cine de autor que se oponía al cine más comercial y a las grandes producciones norteamericanas.

2 Además de Rapado (1992), Silvia Prieto (1999) y Los Guantes Mágicos (2003), sus tres largometrajes de ficción, Rejtman ha dirigido Copacabana (2006), un documental sobre el carnaval de la comunidad boliviana en Buenos Aires, Entrenamiento Elemental para Actores (2009, junto con Federico León), realizada para Canal 7, y dos cortometrajes, Doli vuelve a casa (1984-2004) y Sitting on a Suitcase (1986). Entre su obra literaria hay que mencionar los libros de cuentos Rapado (Planeta, 1992), Velcro y Yo (Planeta, 1996), Literatura y Otros Cuentos (Interzona, 2005) y Tres Cuentos (Mondadori, 2012), así como la publicación del guión de Silvia Prieto (Norma, 1999) y de Entrenamiento Elemental para Actores, en colaboración con Federico León (La Bestia Equilátera, 2013). Por su parte, Doris Dörrie es una prolífica escritora y cineasta. Lleva realizadas más de 15 películas y publicados una decena de libros de cuentos y novelas, además literatura infantil y una obra de teatro. De ellos se han traducido al español Hombres, hombres... (y otros relatos) (1988, Seix Barral, cuentos), ¿Qué quiere usted de mí? y otros relatos (1990, Seix Barral, cuentos), El hombre de mis sueños (1995, Juventud, novela), ¿Y ahora qué hacemos? (2002, Galaxia Gutenberg, novela), Desnudos (2003, Galaxia Gutenberg, drama), El vestido azul (2003, Galaxia Gutenberg, novela) y Luisa quiere ser princesa (2004, Loguez, literatura infantil).

3 Es interesante también todo lo que ocurre alrededor del video de bodas de Marcelo y Silvia. Primero, Marcelo lleva a Brite a comer a la casa de su ex mujer para mirar juntos el video. A su vez, este video va a reemplazar al de los otros dos casamientos de la película: el de Garbuglia y Marta (pagado por el canal) y el de Brite y Marcelo (que aprovechan la fiesta pagada por el canal para casarse sin que se den cuenta). Este mismo video es el que Silvia le muestra a Walter, el ex-presidiario que sale de la cárcel cuando ella va a buscar a Gabriel. Gabriel le había pedido que le grabe el casamiento de la tele, pero ella programó mal el VCR, entonces le muestra a Walter, el compañero de celda de Gabriel, su propio video, como si todos los casamientos dieran lo mismo. Al respecto, Gonzalo Aguilar afirma que "lo que Silvia hace acá es un acto de desprendimiento: deja que la serie haga sus cosas mientras ella se declara prescindente" (Aguilar, 2010: 90).

4 Mariana Sanjurjo (2007) trabaja en profundidad el tema de la identidad en las películas de Rejtman a partir de tres ejes: los nombres, los cuerpos y los lugares. Según Sanjurjo, en las películas de Rejtman se produce una "puesta en tensión de estructuras identitarias" (138) entendidas en términos modernos, es decir, "la unidad de consciencia de un sujeto que es dueño de sus propios pensamientos, acciones y cuerpo, y puede atribuirlos todos a un origen inequívoco (...). En contraposición a esta noción de identidad caracterizada por la unidad, la propiedad de sí y la transparencia (...), la noción de identidad que se despliega en los filmes de Rejtman resiste desde la tensión los intentos por reconducirla a un núcleo elucidado o elucidable de mismidad" (138).

5 El apodo "lámpara de botella" también aparece primero como un significante sin significado ni referencia, ya que Marcelo sabe que llamaban así a alguien pero no recuerda ni a quién ni por qué. Por otro lado, las confusiones entre los tres personajes masculinos funcionan como un gag que recorre la película. Se conocen de chicos, de adolescentes, pero el tiempo ha borroneado los recuerdos y no saben quién es quién.

6 Es importante destacar la importancia del primer plano en la retórica cinematográfica, ya que sirve para generar identificación en el espectador. En particular, el primer plano del rostro y la mirada es lo que le da humanidad al personaje y hace que trascienda la pantalla del cinematógrafo para convertirse en persona real. Al respecto, resulta muy irónico que uno de los pocos primeros planos de la película esté dedicado a una muñequita.

\section{Pour citer cet article}

\section{Référence électronique}

Atilio Raúl Rubino, «Literatura/cine : el cuerpo y la sexualidad en los textos culturales de Doris Dörrie y Martín Rejtman », TRANS- [En ligne], | 2014, mis en ligne le 24 février 2014, consulté le 28 février 2014. URL : http://trans.revues.org/978 


\section{À propos de l'auteur}

Atilio Raúl Rubino

IdIHCS-UNLP

\section{Droits d'auteur}

Tous droits réservés

\section{Résumés}

This paper studies the cinematic and literary texts of two film directors: the German Doris Dörrie and the Argentine Martin Rejtman. The analysis emphasizes the representation of the body and sexuality in their work. Both authors problematize the identity processes, their intention is to show that both, identities and bodies, are crossed by many social discourses that constitute them.

Este trabajo se propone analizar los textos literarios y cinematográficos de la alemana Doris Dörrie y el argentino Martín Rejtman, haciendo especial énfasis en la representación del cuerpo y la sexualidad. En ambos autores se complejizan los procesos identitarios poniéndose de manifiesto que las identidades y los cuerpos están cargados de discursos sociales que los constituyen. 